\title{
Processes for alcohol-free beer production: a review
}

\author{
Carlos MULLER ${ }^{1}$, Luis Eduardo NEVES ${ }^{1}$, Luciana GOMES ${ }^{1}$, Munique GUIMARÃES ${ }^{1}$, Grace GHESTI ${ }^{1 \star}$
}

\begin{abstract}
Since the invention of beer by the Sumerian people in 5000 BC, alcohol was the main reason of the interest of consumers on beer. Only in the beginning of the 20th century alcohol-free beer was demanded and since then technology has advanced dramatically in the production of those beverages. The aim on alcohol-free beer production is to have products that taste similarly to their alcoholic equivalents, the sole absence of alcohol and low concentrations of esters and higher alcohols and the higher concentration of aldehydes create a "worty" organoleptic impression of those products. Alcohol-free beers can be obtained by the restriction of alcohol formation during fermentation, the use of special yeast strains that consume or don't produce alcohol, the thermal removal of alcohol and by the removal of alcohol trough membrane processes. Membrane separated alcohol-free beers preserve more of the natural constituents of beer aroma and those products usually taste better than those obtained through other processes. Pervaporation techniques show a broad spectrum of use and can even be combined with other processes and perform the removal of undesired products or separation and recuperation of aromatic substances.
\end{abstract}

Keywords: alcohol-free beer; membrane separation; alcohol removal; dealcoholized beer.

Practical Application: Alcohol-free beers production. Brewing process of non-alcoholic beers.

\section{Introduction}

\subsection{Alcohol-free beer history}

The origin of the civilizations took place in the Fertile Crescent or Mesopotamia, region nowadays comprised in the territories of Syria and Iraq, it is associated with the fist settlement of the Sumerian people who would have abandoned the nomadic habits to dedicate themselves more intensively to agriculture. And, in turn, the beginning of agriculture would have been motivated by the growing demand for a product newly created by this people, beer (Braidwood et al., 1953). In addition to the aforementioned selective advantages attributed to beer drinkers in that period, due to the high nutritional quality of this ancestral beer, one of the factors that attracted most of these people to beer was its intoxicating effect, derived from the alcohol produced by the alcoholic fermentation (Katz \& Voigt, 1986). However, in a much later period than the onset of civilization, these intoxicating effects became less desirable as they once were, and although the beer continued to be desired, it could no longer contain alcohol, so the origin of beers without alcohol could be attributed to the period known as the United States' Prohibition time. Between 1920 and 1933, US breweries were prohibited from brewing beer and therefore were forced to focus their productive efforts on other products that used the same type of factory structure and operating procedures. Among the products produced by the breweries at that time were dyes, malt extracts and a new malt-based drink, called "near beer", which contained less than $0.5 \%$ alcohol, so its production was allowed at that time (Bamforth, 2006). Almost simultaneously to the period of the North American Prohibition, the reduction in the supply of cereals in the European market due to the changes caused by the first world war led to the development of beer of lower alcohol content by the consequent reduction on the availability of raw materials and its use in the production of other foods such as baked goods (Briggs et al., 2004). Although there have been patent registrations of non-alcoholic or low-alcohol beers since the last decade of the nineteenth century, this class of products saw their consumption grow and reach statistically measurable levels almost 100 years after, with the entry into force of legislations in the US and Europe that limited the intake of alcohol for drivers (Bamforth, 2006). Since then, with the increasing association of alcohol consumption with health problems and the increase in the strictness of norms restricting the consumption of beverages associated with the direction of automobiles, the consumption of non-alcoholic beers has grown worldwide in remarkable levels, reaching in countries such as Spain, a proportion of about $10 \%$ of the total beer market in 2010 (Gaetano et al., 2016).

\subsection{Health and market}

Although recent epidemiological studies have shown that moderate consumption of beer, one to two glasses a day, can reduce the risk of coronary heart disease (Gaetano et al., 2016), hypertension and diabetes, in countries where alcohol consumption is prohibited by law, non-alcoholic beers become interesting alternatives to other non-alcoholic beverages because they bring much of the bioactive components of traditional beer without the harmful effects of alcohol in these cases (Gaetano et al., 2016).

Such desirable effects of non-alcoholic beers have boosted their consumption worldwide, while sales of alcoholic beers are practically stable or declining in most markets, such as the European countries, the United States and Japan, sales of 
non-alcoholic beers have been growing worldwide taking part of the market for alcoholic beers, other non-alcoholic beverages and also exploring new markets in Islamic countries such as Saudi Arabia and the United Arab Emirates, where alcohol consumption is banned (The Economist Explains, 2013).

In Brazil from 2010 to 2014, the consumption of non-alcoholic beer grew by $5 \%$, against $3 \%$ for regular beers during the same period, reaching in July 2014 a slice of $1 \%$ of all beer sales in the country, a considerable amount taking into consideration the total turnover from a sector that circulates around seventy billion Brazilian real (roughly 22 billion US dollars) a year with a production of 14 billion liters of beer every year (Salles, 2015).

\subsection{Legal aspects}

The maximum values of alcoholic content of non-alcoholic beers defined by the specific legislation of several countries vary widely. In Brazil and Mercosur, non-alcoholic beers are legally defined and classified as such, if their alcohol content is less than or equal to one-half percent by volume, and as beer with alcohol, when their alcohol content is higher than one-half percent by volume (Brasil, 1994). It is noteworthy that another aspect to be taken into account for the proper framing of the product is its form of production, since Brazilian legislation defines beer as being the drink obtained by the alcoholic fermentation of the brewing wort from barley malt and potable water, by action of yeast, with the addition of hops (Brasil, 2009). Therefore, beer must be obtained by fermentation of the brewer's wort, which prevents the marketing of brewer's wort or other non-alcoholic, non-fermented beverages, derived from malt, under the name of non-alcoholic beers (Brasil, 2009).

According to the legislation in force in Germany the term Alkoholfrei, or without alcohol, is applied in the same parameters defined for Brazilian legislation, i.e. beers containing up to $0.5 \%$ alcohol by volume (Kunze, 2010). On the other hand, in the United States of America the term alcohol-free beer is exclusive to products which have no detectable residual alcohol content, whereas products with an alcohol content of up to $0.5 \%$ by volume are referred to as non-alcoholic (Food and Drug Administration, 2005). A similar definition applies to products sold in the United Kingdom, as well as in the USA it may only be termed non-alcoholic beer, if it contains up to $0.05 \%$ residual alcohol content, whereas they are referred to as dealcoholized products if its alcoholic strength is between $0.05 \%$ and $0.5 \%$ by volume and of low-alcohol (low alcoholic strength) with an alcoholic strength of $0.5 \%$ to $1.2 \%$ by volume (Briggs et al., 2004).

\subsection{Justification}

Alcohol-free beer production didn't changed much since it was developed until the late century XX, the methods applied to its production were mainly the restriction of alcohol formation by means of interrupted or incomplete fermentations (Briggs et al., 2004; Kunze, 2010). However, the recent growing demand products and the availability of new technologies and materials lead to a much dynamic development of alcohol-free beer brewing methods in the last 20 years. Therefore, this review is focused on prospecting the latest development registered on these technologies providing a prospect on the current "state of the art" of alcohol-free beer production.

\subsection{Comparison between organoleptics characteristics of beer with and without alcohol}

The typical flavors of beer are the result of the combination of hundreds of compounds present in this beverage, where not only the amount of each of these compounds changes the flavor of the drink in isolation, but also its interaction with the others causes alterations in the organoleptic sensations perceived by those who consumes it (Vanderhaegen et al., 2003).

The great challenge presented to all breweries that produce non-alcoholic beers is to develop products that have organoleptic characteristics that are as close as possible to the original beers and thus present a greater acceptance of their consuming public (Silva et al., 2015). However, the processes of obtaining non-alcoholic beers in one way or another end up damaging their aroma and taste either by restricting the formation of compounds in incomplete fermentations, by the loss of volatile compounds during alcohol withdrawal steps or by the absence of alcohol itself (Andres-Iglesias et al., 2015).

Among the compounds that have their formation impaired and are easily lost due to their volatility are the esters of ethyl and acetate groups. These groups are the most important constituents in the formation of the aromatic profile of beer due to their low detection threshold when compared to other metabolites from the yeasts, promoting their easy recognition and importance in the aroma of beers, even if their concentrations are lower than 1ppm (Pires et al., 2014).

Esters are products of condensation reactions of carboxylates with ethanol and higher alcohols (as mentioned in Table 1), so under conditions of restricted alcohol formation there is insufficient formation of esters which impairs the final aroma of the beer (Bart, 2013).

Perpète \& Collin showed that the common perception that non-alcoholic beers have a similar taste to brewer's wort and it is related to the high concentrations of 3-methylthiopropionaldehyde and other aldehydes in these products (Perpète \& Collin, 2000). This happens because in interrupted fermentations or contact with cold yeast, there is not enough degree of reduction of these aldehydes in order to make them imperceptible. In the other processes of beer dealcoholization, ethanol promotes the retention of these compounds at considerable levels only in concentrations above $0.5 \%$ (Perpète \& Collin, 2000).

\subsection{Alcohol-free beer brewing methods}

The known methods of obtaining non-alcoholic beer can be divided into two major groups - restriction of the formation of ethanol and removal of ethanol. All having their advantages and disadvantages listed below.

\subsection{Restriction of alcohol formation}

In general, in the biological processes of obtaining non-alcoholic beer, the wort is not completely fermented, either with interruption of fermentation, cold fermentation, use of selective microorganisms with greater affinity to specific parts of wort. The final product usually has a sweeter sensory 
Table 1. Secondary metabolism of aroma compounds (Bamforth, 2006; Briggs et al., 2004).

\begin{tabular}{|c|c|c|c|}
\hline Substrate & Process & Product & Observations \\
\hline Acetolactate & $\begin{array}{l}\text { Oxidation of Acetolactate, } \\
\text { intermediate compound in Valine } \\
\text { synthesis. }\end{array}$ & 2,3-Butanedione (Diacetyl) & $\begin{array}{l}\text { Unpleasant butter-like aroma and } \\
\text { flavour, it is naturally consumed by } \\
\text { yeast. }\end{array}$ \\
\hline Dimethyl sulfoxide (DMSO) & Reduction of DMSO to DMS. & Dimethyl Sulphide (DMS) & $\begin{array}{l}\text { Unpleasant aroma of cooked } \\
\text { vegetables and corn. }\end{array}$ \\
\hline Ferulic Acid & Decarboxylation of ferulic acid. & 4-vinyl guaiacol & $\begin{array}{l}\text { Characteristic clove-like aroma of } \\
\text { certain beer styles. }\end{array}$ \\
\hline Wort's amino acids & $\begin{array}{l}\text { Deamination, decarboxylation e } \\
\text { reduction of amino acids (Ehrlich } \\
\text { mechanism). }\end{array}$ & Higher alcohols & $\begin{array}{l}\text { In concentration about } 90 \mathrm{ppm} \text {, they } \\
\text { have a typical and desired aroma, at } \\
\text { higher concentrations they can cause } \\
\text { unpleasant aromas and headaches. }\end{array}$ \\
\hline Acetyl-CoA + alcohols & $\begin{array}{l}\text { Biosynthesis through Acetyl-CoA } \\
\text { synthetase and alcohol } \\
\text { acyltransferase }\end{array}$ & Esters & Main aroma components of beer. \\
\hline
\end{tabular}

characteristic, enhanced wort like flavor and more vivid color. The greatest advantage of biological processes in relation to physical-chemical processes is that, in most cases, there is no need to install additional equipment in the industrial plant for the extraction of alcohol (Eßlinger, 2009).

\subsection{Interrupted fermentation}

This method uses the same equipment used in the traditional beer fermentation, which represents an advantage in the adaptation of a plant already in operation that manufactures this type of product. This can be obtained through the use of yeasts that perform a partial fermentation of the wort, with the removal of the yeasts and thus stopping the fermentative process. The interrupted fermentation avoids the process of dealcoholization and all the difficulties inherent to such process. The disadvantages of this method arise from the fact that the time required for the fermentation is not sufficient to obtain a beer without alcohol nor to promote an adequate conversion of the wort to beer (Eßlinger, 2009), which results in a final product poor in aromatic compounds and with a strong characteristic of wort. Generally, sensorial flaws of final beer are corrected with the addition of distinct flavorings for each type of product "defect", such as isoamyl acetate, which banana odor and flavor overlaps with the undesired worty flavor (Eßlinger, 2009).

\subsection{Cold yeast contact}

This method also uses the same equipment used in traditional beer fermentation, with the differential that all fermentation is carried out at low temperatures. An important feature of this method is that the yeast reduces carbonyl compounds from the wort, which enables the production of aromatic compounds, but these yeasts can convert amino acids into aldehydes which contribute to the formation of off-flavors. In general, cold-fermented non-alcoholic beers have characteristics similar to common beer (Sohrabvandi et al., 2010).

\subsection{Utilization of special yeast}

There are a large number of known yeasts suitable for this type of process. An example would be Saccharomyces rouxii spp., which is considered a yeast of low alcohol production from the wort for its inefficiency in degrading maltose, the most abundant sugar of the wort (Sohrabvandi et al., 2010). This yeast acts on wort partially fermented by S. cerevisae and reduces the alcoholic strength of the wort with alcohol degradation and high formation of acetaldehyde, diacetyl and 2,3-pentanedione (Sohrabvandi et al., 2010), such compounds are known as off-flavors.

Other yeasts used would be mutant yeasts, such as Saccharomyces ludwigii, strains with increased production of glycerol by the elimination of alcohol dehydrogenase and strains with over expression of glycerol-3-phosphate dehydrogenase (Strejc et al., 2013). Cultures of Lactobacillus spp. (Eßlinger, 2009) or Saccharomyces pastorianus (Sohrabvandi et al., 2010) can also be used. Generally, special microorganisms produce a beer with a sweet or fruity final characteristic with a low bitterness, or acid in the case of the addition of Lactobacillus spp.

\subsection{Utilization of immobilized yeast or bioreactors}

This process consists in the use of yeasts attached to a carrier material, such as DEAE-cellulose, calcium alginate, calcium pectate or sintered glass. The carrier material and the yeast are placed in a reactor, where the wort flows. The immobilization of yeasts induces a higher biomass per unit of the reactor in volume in a shorter run time. In the use of bioreactors there is the formation of the aromatic compounds characteristic of beer, with good yield, but the process is difficult to control, the equipment has a high cost and risk of microbiological contamination, requiring greater care in the filtration, stabilization and pasteurization of the beer produced (Eßlinger, 2009). There are several equipment models for fermentations with immobilized yeast, such as stirring tank bioreactors, tower bioreactors with air flow or with backflow between air and product.

A new strand in bioreactors in the production of low-alcohol beer could be the use of microbiological fuel cells (MFC) in the fermentation with concomitant generation of electricity in the process (Williams, 2002).

\subsection{Ethanol removal}

All listed ethanol removal processes involve additional costs for the production plants with the installation of specific equipment, and the vast majority, if not all, include the removal 
of ethanol and a large part of the aromatic compounds of the beer, impacting on its final sensory properties. The ethanol removal is divided into three major groups: thermal treatments, extraction and membrane processes. Each having advantages and disadvantages listed below.

\subsection{Thermal treatment}

The thermal processes of beer dealcoholization generally alter the final product sensorially, with loss of aroma, body, carbonation and flavor, as well as changes in the aromatic profile, with intensification of undesirable aromas (Eßlinger, 2009). The thermal processes currently used are vacuum evaporation, vacuum distillation and centrifugation distillation.

\subsection{Vacuum evaporation}

This process utilizes thin layer evaporators with mechanically produced thin films at moderate temperatures of about 37 to $60^{\circ} \mathrm{C}$ and pressure from 60 to $200 \mathrm{mbar}$ (Vanderhaegen et al., 2003). An example of equipment would be the downflow evaporator, which consists of columns from four to five meters high with heating tubes, through which the beer is heated to a temperature of $45^{\circ} \mathrm{C}$ under vacuum. In a downward flow alcohol is volatilized and separated into a condenser. The beer is partially dealcoholized and subjected to this process again in a second downflow evaporator and finally dealcoholized to approximately $0.05 \%$ by volume (Kunze, 2010). This method allows obtaining a beer having an alcohol content below 0.05 vol\% when a rectifying column is coupled to the evaporator. The disadvantages of this process are the high energy costs and the need to install an additional evaporator in the plant. The thermal process adversely impacts temperature sensitive compounds and some volatile flavorings such as the esters of the ethyl and acetate groups are extracted together with ethanol, resulting in a beer having a coloration of about 0.5 to $1.5 \mathrm{EBC}$ units (European Brewers Convention) above the original beer, in addition to a decrease of 1 to 2 EBC bitter substances units, increase of the actual extract, increase of $\mathrm{pH}$ around 0.1 to 0.2 and loss of volatile organic acids and CO2 (Eßlinger, 2009).

\subsection{Vacuum distillation}

In this process, described below in Figure 1, the beer (1) is heated in a plate heat exchanger $(2)$ at $45^{\circ} \mathrm{C}$ and subsequently brought to a flavor stripper (3) where the pressure is reduced rapidly. As a result, the volatile aromatic components of the beer are evaporated, which are then added back into the recombination tank. Thereafter, in the vacuum column 4 the alcohol is released from the beer at about $40^{\circ} \mathrm{C}$ and is decanted into a spray condenser. The beer is desalted and refrigerated in a heat exchanger at a temperature of $4^{\circ} \mathrm{C}$ to $5^{\circ} \mathrm{C}$ and in the after cooler at a temperature between 0 and $1^{\circ} \mathrm{C}$. In the recombination tank the beer is mixed with the previously extracted volatile aromatic substances (Kunze, 2010). This process can reduce the alcohol content of beer to about $0.05 \mathrm{vol} \%$ The use of the vacuum in this process also allows the use of moderate temperatures. The disadvantages of this process are the high energy costs, the need to use an additional distillation column in the plant and volatile flavors are extracted together with the ethanol, resulting in a less complex beer.

\subsection{Spinning cone column}

This process consists of running the beer into a thin film form onto a heated surface of centrifugal disks. Due to the influence of the centripetal force, the beer is thinned between the disks and heated by steam, which is supplied through the double wall of the centrifugal evaporator (Figure 2). In this process the alcohol evaporates and is withdrawn, the beer with

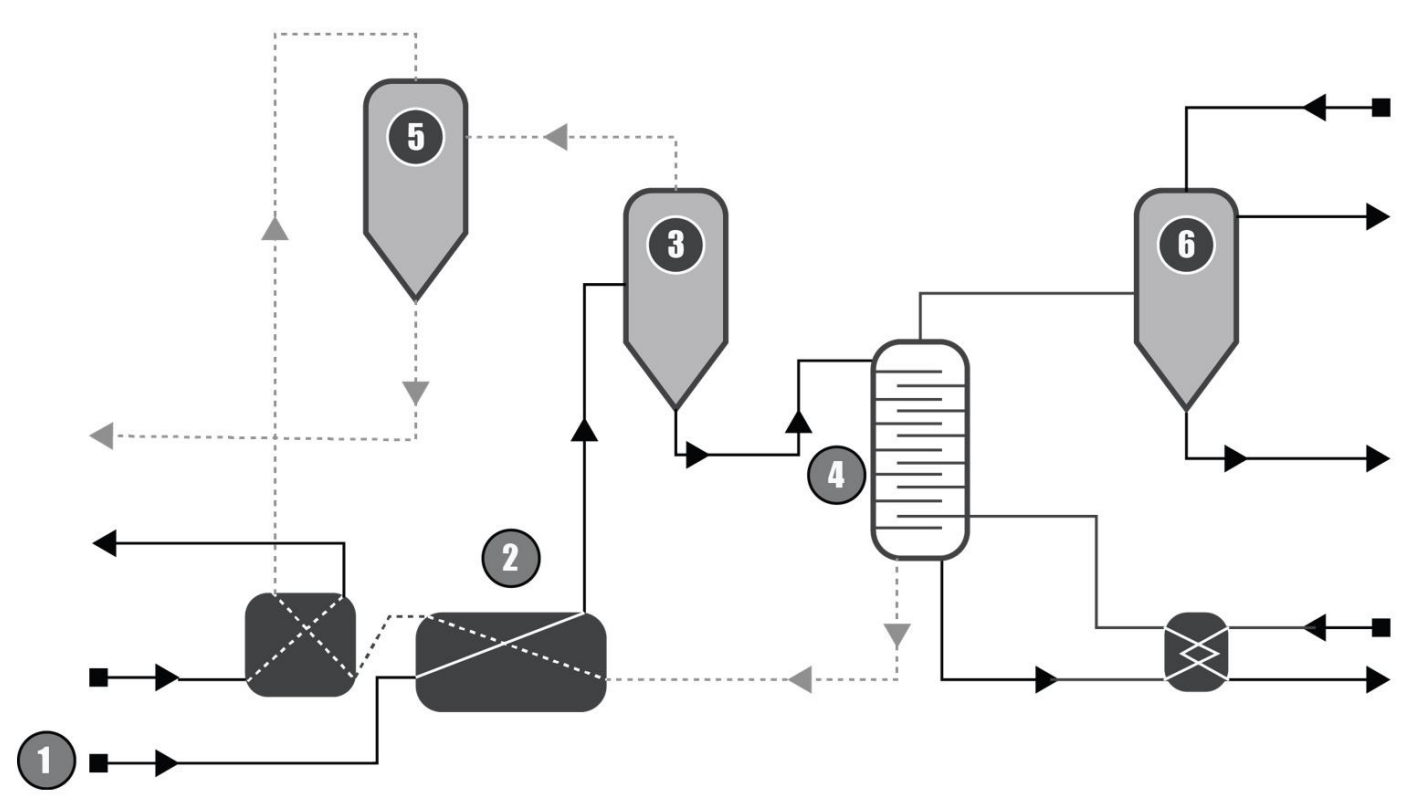

Figure 1. Vacuum distillation plant. (1) beer input, (2) plate heat exchanger, (3) aroma stripper, (4) vacuum column, (5) recombination tank, (6) pulverization condenser (Kunze, 2010). 
reduced alcoholic content undergoes pressure out of the system and extracted through an output disc. The process is carried out under vacuum at temperatures of 30 to $34{ }^{\circ} \mathrm{C}$. Each step of this process takes less than 10 seconds and for this reason is repeated several times 11 in order to obtain a beer with an alcohol content of about $0.05 \mathrm{vol} \%$. In this process, although it also results in the need to use additional equipment, with coupling of a rotating cone column and high energy costs, the turbulent flows and the high need of contact area between the two phases, end up having a lower thermal impact In the product, allowing a low residence time and moderate temperatures on the drinks, without, however, removing volatile aromas and compounds that formed the original beer aroma (Catarino, 2010).

\subsection{Extraction}

The alcohol extraction processes can be divided into solvent extraction, in this case with supercritical carbon dioxide and adsorption extraction.

Extraction is a method in which a component is removed, or separated, from a system by contact with another material or phase, having a higher affinity for that particular component. Three steps can be observed in the process; the mixture of the raw material with the solvent, in order to bring into contact, the separation of the two phases, and the removal of the solute, that is, the component extracted from the solvent in such a way that the solvent can be recycled (Karlsson \&Trägårdh, 1997). Solvent extraction for non-alcoholic beer consists of the use

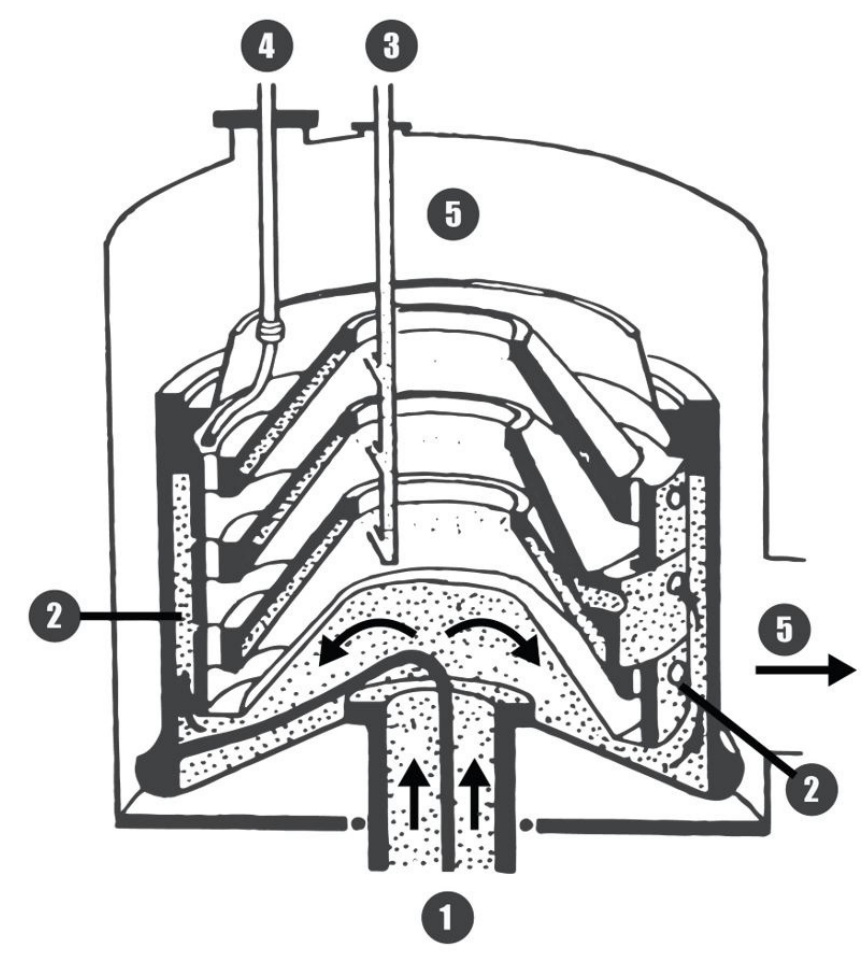

Figure 2. Spinning Cone Column - (1) steam inlet and condensate outlet, (2) distribution of steam to the heatable centrifuge discs, (3) beer inlet, (4) outflow of the partially dealcoholized beer, (5) removal of the alcohol containing steam (3). of water-immiscible solvents with high solubility in ethanol in order to attract beer to a solvent with which it has the highest affinity, i.e. extraction of ethanol occurs with liquid carbon dioxide. In some conditions of temperature and pressure, the carbon dioxide has properties similar to the organic solvents, in that process the carbon dioxide also removes some important aroma compounds, and a first phase the carbon dioxide is used for the extraction of aroma compounds which are added to the dealcoholized beer in a second stage. Different operating conditions of the two phases influence the selective extraction of aroma and ethanol compounds. This process involves a high cost of operation, with the need of coupling an additional extraction unit to the industrial plant, but has the advantage of being carried out at room temperature, avoiding the thermal impact on beer (Ruiz-Rodríguez et al., 2012).

Adsorption extraction consists of the use of hydrophobic adsorbents, such as zeolites with a Si:Al ratio greater than 12. In this process, the organoleptic characteristics of the final product are well preserved when compared to the original product. The beer is inserted under pressure through carbon dioxide in a column coated with zeolite, the percolation of the beer is continuous until the eluent has a low alcohol concentration. In the eluent, most of the characteristics of the original beer are preserved and stored in a tank. Desorption of the aromatic and alcoholic products trapped in the hydrophobic zeolite is accomplished by elution or heating. The elution can be carried out by a solvent, it being necessary to separate this solvent later, a good method is the use of supercritical carbon dioxide fluid. The charged gas passes through a separator in which the alcohol is volatilized and separated from the trapped aromatic compounds which are subsequently reattached to the original product. This process involves high operating costs, requiring a specific additional equipment, the separation unit (Figure 3), and after the end of the process the adsorbent must be regenerated by super critical $\mathrm{CO} 2$ and heat. (Gamse et al., 1999)

\subsection{Membrane separation processes}

Membrane separation processes offer some competitive advantages to the other non-alcoholic beer production processes because these processes operate at mild temperatures, with low energy consumption and with little or no need for use of

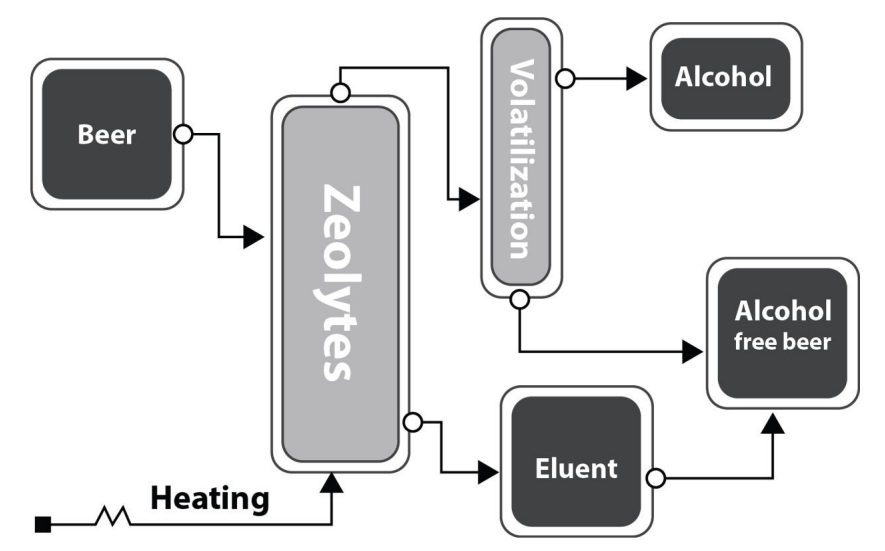

Figure 3. Flowchart of the adsorption process. 
chemical additives or technology enhancing agents, which reduce the negative impact of these methodologies on the product while at the same time presenting reduced operating costs (Ambrosi et al., 2014), although there is still a need to obtain additional equipment from existing industrial plants. These include nanofiltration, reverse osmosis, osmotic distillation, dialysis and pervaporation.

\subsection{Nano filtration}

The nanofiltration process consists of the separation of solutions by means of membranes, which select particles with sizes larger than $2 \mathrm{~nm}$ by pressurizing the solution to be filtered, according to Figure 4 (Mueller et al., 2012). Polymeric or ceramic membranes are used, which do not have detectable pores resembling the membranes used in reverse osmosis (Mueller et al., 2012).

In essays done with the dealcoholization of white and red wines, it was detected that the reduction of the alcoholic degree of these products by up to $3 \%$ by nanofiltration reduces the levels of total acidity and volatile substances, anthocyanins and increases the color intensity, but this same work concludes that the changes indicated do not disqualify these non-alcoholic beverages from their alcoholic equivalents (Lança, 2011).

To date, there is no extensive literature available on this methodology applied to the production of non-alcoholic beers, but results obtained with other beverages indicate a promising field of research applied to the dealcoholization of beers.

\subsection{Reverse osmosis}

The osmosis process is defined as the flow of solvent through a semipermeable membrane from a less concentrated to a more concentrated solution, seeking the so-called "osmotic equilibrium" between the two solutions (Meschia \& Setnikar, 1958). In processes of dealcoholization of beers by reverse osmosis this process is redesigned in such a way that the alcohol and the water of the beer to be dealcoholized are filtered through a semipermeable membrane in the opposite direction to the osmotic pressure of the solutions employed, configuring the reverse character of this operation (Kunze, 2010). With the use of the reverse osmosis process, the beer obtained will hardly ever have an alcohol content below $0.45 \%$ vol., with a more complete but slightly acidic taste, with a greater loss of bitter substances and a slight increase in turbidity, less than one color unit EBC (Eßlinger, 2009). Diafiltration water is used and beer is treated at low temperature and high pressure, which is beneficial for beer, but the membranes used have high retention of aromatic compounds (Purwasasmita et al., 2015).

\subsection{Osmotic distillation}

Osmotic distillation is a dealcoholization process in which the energy utilization is highly efficient as compared to reverse osmosis or distillation (Purwasasmita et al., 2015). This process is carried out at low temperature, low operating pressure, with low interaction between the membrane and the Liquids involved in the process, but the preparation of the system feed solution must be done in a cautious manner to avoid damage to the membrane (Kunze, 2010).

This process has as main disadvantage the removal of volatile compounds, which are lost without the coupling of a recovery unit, $\mathrm{CO}_{2}$ is also lost in the process and this can be easily added to the drink (Liguori et al., 2016). The selectivity of the process is determined by the equilibrium between the liquid and vapor concentration in the system, since the component that presents the highest partial pressure suffers the highest permeation rate of the membrane (Purwasasmita et al., 2015).

\subsection{Dialysis}

The principle of dialysis is based on the selective diffusion of substances through a semipermeable membrane, as the rate of separation by dialysis is based on the concentration gradient and

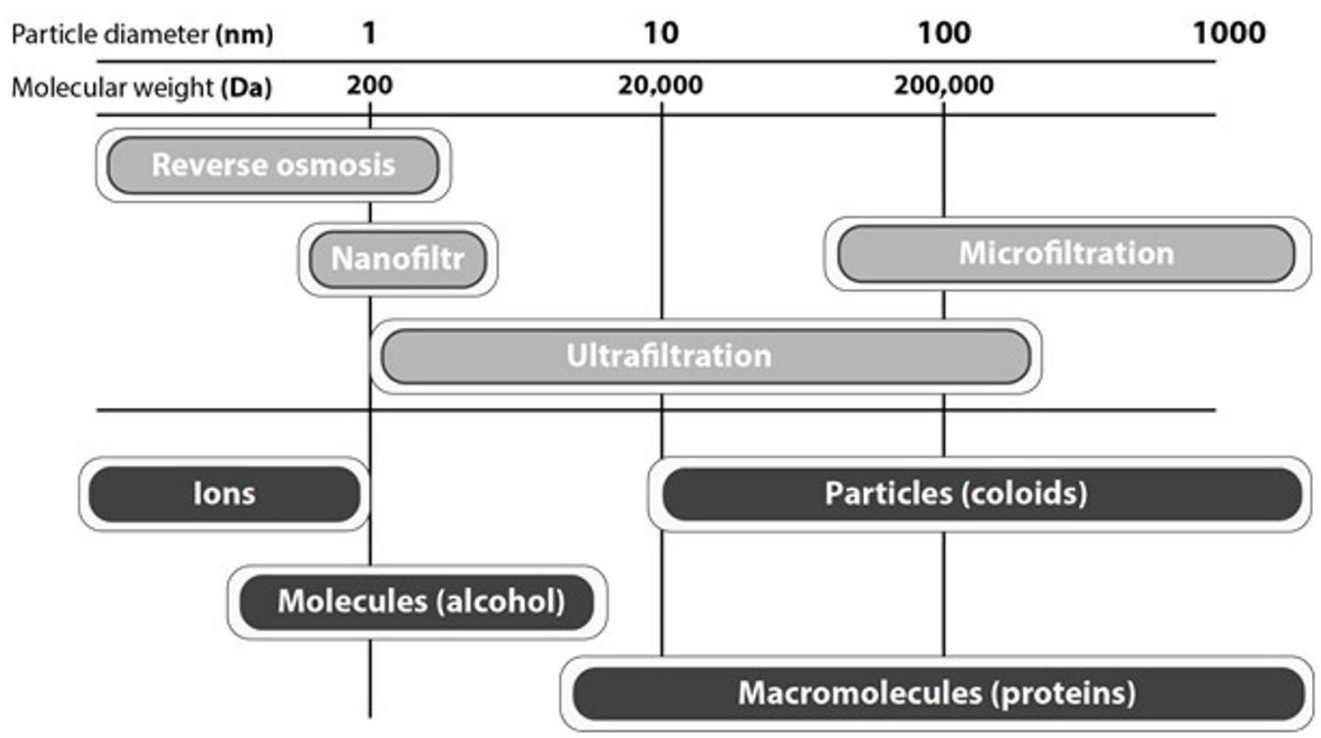

Figure 4. Comparison between separation methods. Adapted from (Mueller et al., 2012). 
inversely proportional to the size of the molecules in the case of beer the alcohol is preferably diffused through of the membrane (Moonen \& Niefind, 1982). The dialysis dealcoholization processes employ tubular capillaries with diameters ranging from 50 to $200 \mu \mathrm{m}$ with walls not thicker than $25 \mu \mathrm{m}$. The beer is pumped through these micro tubes while water or other solution of known concentration is pumped in reverse flow on the outside of these tubes. The alcohol is then withdrawn from the beer as it passes through this tubular semipermeable selective membrane seeking equilibrium of the alcoholic concentration between the solutions of the inner and outer sections of the tubes. As the backflow system allows, the concentration of alcohol outside the tube is always lower than that of the interior, which promotes extensive removal of alcohol from the beer during the entire process of pumping through the capillaries (Kunze, 2010). In dialysis beer is treated at low temperatures, and membrane selectivity and procedures during the process interfere greatly in the composition of the final product, according to Figure 5 (Pires et al., 2014). As beer is treated at low temperatures there is no thermal degradation of the product, nor is there significant concentration or loss of water, dispensing the adjustment of the product after the treatment (Moonen \& Niefind, 1982).

\subsection{Pervaporation}

The process of dealcoholization by pervaporation consists in the separation of the alcohol by the use of selective semipermeable membranes in a process of diffusion of the filtrate (alcohol) in its gas phase at low temperatures. Such a methodology can also be classified as a nanofiltration, given the nature of the membranes employed and the size of the particles selected from the solution (Verhoef et al., 2008). Transport through the membrane occurs due to a difference in chemical potential between the substances separated by the membrane, where the molecules of alcohol permeate the membrane in the direction from the highest alcoholic concentration to the lowest (Mattos \& Queiroz, 1998). This technology makes use of polymeric membranes usually constituted by Polydimethylsiloxane and Polyoctylmethylsiloxane (Verhoef et al., 2008). In addition to the removal of alcohol, one of the main uses of pervaporation technology is its use in the extraction and concentration of volatile beer compounds so that they are later re-applied to non-alcoholic beer, this is done by handling the parameters of the pervaporation temperature with The suitability of the constituents of the membrane in order to adjust the selectivity of the process according to the desired product (Olmo et al., 2014). This possibility of aroma recovery allows this methodology to be used in association with other methods of producing non-alcoholic beers, in which aromas may be lost or even formed during processing, in this way higher esters and alcohols may be withdrawn from conventional beers or beer to be dealcoholized and subsequently added to the final alcohol-free beer (Ambrosi et al., 2014).

\subsection{Comparison of the processes and its associations}

A general evaluation of the biological, thermal, extraction and membrane processes is described below at Table 2 .

Biological processes such as, interrupted fermentation, cold yeast contact and Bioreactors of immobilized yeast display incomplete or very short fermentations, so typical beer flavors are not present and, due to that, these beers usually have lower organoleptic qualities. When special yeast strains are used undesirable off-flavors are formed and again the beer does not have a suitable organoleptic characteristic. On the other hand, these processes usually have low installation costs, since new equipment or installations are not needed.

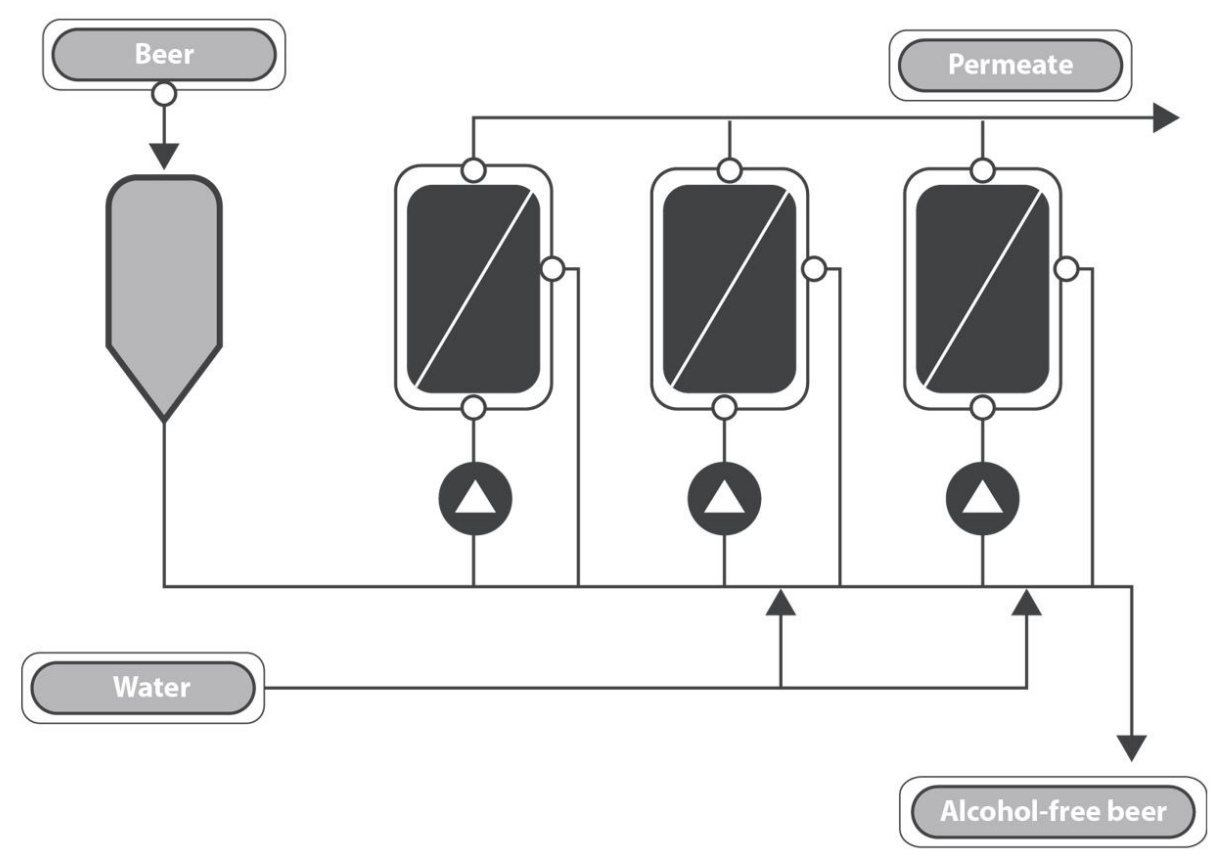

Figure 5. Flowchart of the dialysis dealcoholization process. 
Table 2. Comparison of installation costs, operational costs, yield and quality of the final beer of the main processes used and its associations in order to obtain dealcoholized beer.

\begin{tabular}{|c|c|c|c|}
\hline PROCESS & INSTALATION COSTS & OPERATION COSTS & BEER QUALITY \\
\hline \multicolumn{4}{|l|}{ BIOLOGICAL PROCESSES } \\
\hline Interrupted Fermentation & * & $* * *$ & * \\
\hline Cold Yeast Contact & $* *$ & ** & * \\
\hline Utilization of Special yeast & $* *$ & ** & * \\
\hline Utilization of Immobilized Yeast or Bioreactor & * & ** & * \\
\hline \multicolumn{4}{|l|}{ THERMAL PROCESSES } \\
\hline Vacuum Evaporation & ** & * & * \\
\hline Vacuum Distillation & $* *$ & * & $* *$ \\
\hline Spinning Cone Column & $* *$ & ** & $* *$ \\
\hline \multicolumn{4}{|l|}{ EXTRACTION PROCESSES } \\
\hline Extraction with $\mathrm{CO}_{2}$ & ** & ** & $* *$ \\
\hline Adsorption Extraction & ** & ** & $* * *$ \\
\hline \multicolumn{4}{|l|}{ MEMBRANE PROCESSES } \\
\hline Nanofiltration & $* *$ & ** & $* * *$ \\
\hline Reverse Osmosis & $* *$ & * & $* *$ \\
\hline Osmotic Distillation & $* *$ & $* * *$ & $* *$ \\
\hline Dialysis & $* * *$ & * & * \\
\hline Pervaporation & * & ** & $* * *$ \\
\hline
\end{tabular}

where: ${ }^{* *}$ more advantageous and ${ }^{\star}$ least advantageous.

Thermal processes in general promote some volatile compounds loss and some thermal stress on the beer inducing oxidation reactions that will reduce products shelf life and organoleptic quality. This reduced quality of the beers produced implies in less interest on these technologies, despite lower installation and operation costs.

Adsorption processes aren't fully developed to its potential in alcohol free beers production, there are still only laboratory scale experiments being conducted with very promising results. Low energy and inputs demand allied to high organoleptic quality of the beers contribute to the interest on the development of these methods.

Currently, membrane separation technologies are the most advanced industry available alcohol free beer production methods. Benefiting from the development of new nanomaterials used in the membranes, these methods generally produce high quality beers with reduced energy and input use. The reincorporation of extracted beer volatiles enhances the organoleptic characteristics of these products that allied with membrane selectivity plays a major role enhancing the quality of these products when compared to other alcohol free beers.

\section{Conclusion}

The growing consumption of non-alcoholic beers and the recent consumer concerns about the residual alcohol content in these products directed the research and innovation of these products towards the supply of products increasingly similar to their alcoholic equivalents and with the lowest alcohol content possible.

Non-alcoholic beers produced by interrupted fermentation, once widely used, despite having a low operating cost and not requiring severe changes in installed technology, is no longer able to offer products with competitive organoleptic characteristics compared to non-alcoholic beers obtained by others methods available on the market.

Alcohol extraction or adsorption processes have promoted satisfactory results in the dealcoholization of other fermented beverages and may be an interesting alternative for the development of new researches.

Methods of separation of alcohol by membrane are shown as the most appropriate technologies in the search for high-quality dealcoholized products. Advances in the research of nanomaterials and membrane constituent polymers can drastically aid the development of new products and technologies.

The pervaporation technology is an interesting alternative in its use in association with other methods of producing non-alcoholic beers because it allows the reintroduction or addition of natural aromatic compounds to the product or the removal of unpleasant aromas due to the high selectivity of the beer.

Future developments in alcohol-free beer production will benefit from the combination of the technologies cited in this article, membrane-based processes allied to special yeasts or adsorption processes show the potential to be the future trends in this industry.

\section{References}

Ambrosi, A., Cardozo, N. S. M., \& Tessaro, I. C. (2014). Membrane separation processes for the beer industry: a review and state of the art. Food and Bioprocess Technology, 7(4), 921-936. http://dx.doi. org/10.1007/s11947-014-1275-0.

Andres-Iglesias, C., Montero, O., Sancho, D., \& Blanco, C. A. (2015). New trends in beer flavour compound analysis. Journal of the Science 
of Food and Agriculture, 95(8), 1571-1576. http://dx.doi.org/10.1002/ jsfa.6905. PMid:25205443.

Bamforth, C. (2006). Brewing: new technologies. Cambridge: Woodhead.

Bart, R. (2013). The chemistry of beer: the science in the suds. Hoboken: Wiley. http://dx.doi.org/10.1002/9781118733745.

Braidwood, R. J., Sauer, J. D., Helbaek, H., Mangelsdorf, P. C., Cutler, H. C., Coon, C. S., Linton, R., Steward, J., \& Oppenheim, A. L. (1953). Did man onde live by beer alone? American Anthropologist, 55(4), 515-526. http://dx.doi.org/10.1525/aa.1953.55.4.02a00050.

Brasil. (1994, Julho 15). Lei no 8.918, de 14 de Julho de 1994. Dispõe sobre a padronização, a classificação, o registro, a inspeção, a produção e a fiscalização de bebidas, autoriza a criação da Comissão Intersetorial de Bebidas e dá outras providências. Diário Oficial [da] República Federativa do Brasil. Retrieved from: http://www.planalto.gov.br/ ccivil_03/leis/18918.htm

Brasil. (2009, Junho 4). Regulamenta a Lei no 8.918, de 14 de julho de 1994, que dispõe sobre a padronização, a classificação, o registro, a inspeção, a produção e a fiscalização de bebidas (Decreto ${ }^{\circ} 6871$, de 4 de Junho de 2009). Diário Oficial [da] República Federativa do Brasil. Retrieved from: http://www2.camara.leg.br/legin/fed/ decret/2009/decreto-6871-4-junho-2009-588673-norma-pe.html

Briggs, D. E., Brookes, P. A., Stevens, R., \& Boulton, C. A. (2004). Brewing: science and practice. Cambridge: Woodhead.

Catarino, M. (2010). Production of non alcoholic beer with reincorporation of original aroma compounds (Dissertação de mestrado). Universidade do Porto, Porto.

Eßlinger, H. M. (2009). Fermentation, maturation and storage. In H. M. Eßlinger (Ed.), Handbook of brewing: processes, technology, markets (pp. 207-224). Weinheim: Wiley VCH.

Food and Drug Administration - FDA. (2005). CPG Sec. 510.400 dealcoholized wine and malt beverages - labeling. USA: FDA. Retrieved from: https://www.fda.gov/iceci/compliancemanuals/ compliancepolicyguidancemanual/ucm074430.htm

Gaetano, G., Costanzo, S., Di Castelnuovo, A., Badimon, L., Bejko, D., Alkerwi, A., Chiva-Blanch, G., Estruch, R., La Vecchia, C., Panico, S., Pounis, G., Sofi, F., Stranges, S., Trevisan, M., Ursini, F., Cerletti, C., Donati, M. B., \& Iacoviello, L. (2016). Effects of moderate beer consumption on health and disease: a consensus document. Nutrition, Metabolism, and Cardiovascular Diseases, 26(6), 443-467. http://dx.doi.org/10.1016/j.numecd.2016.03.007. PMid:27118108.

Gamse, T., Rogler, I., \& Marr, R. (1999). Supercritical $\mathrm{CO}_{2}$ extraction for utilisation of excess wine of poor quality. The Journal of Supercritical Fluids, 14(2), 123-128. http://dx.doi.org/10.1016/ S0896-8446(98)00114-4.

Karlsson, H. O. E., \& Trägårdh, G. J. (1997). Aroma recovery during beverage processing. Journal of Food Engineering, 34(2), 159-178. http://dx.doi.org/10.1016/S0260-8774(97)00081-2.

Katz, S., \& Voigt, M. (1986). Bread and Beer: the early use of cereals in the human diet. Expedition, 28, 23-34.

Kunze, W. (2010). Technology brewing \& malting. Berlin: VLB,.

Lança, M. (2011). Desalcoolização parcial de vinhos por nanofiltração e osmose inversa (Dissertação de mestrado). Universidade do Porto, Porto.

Liguori, L., De Francesco, G., Russo, P., Perretti, G., Albanese, D., \& Di Matteo, M. (2016). Quality attributes of low-alcohol top-fermented beers produced by membrane contactor. Food and Bioprocess Technology, 9(1), 191-200. http://dx.doi.org/10.1007/s11947-015-1612-y.

Mattos, I. L., \& Queiroz, R. R. U. (1998). Pervaporation: a non-chromatographic continuous separation technique. Quimica Nova, 21(2), 202-205. http://dx.doi.org/10.1590/S0100-40421998000200016.
Meschia, G., \& Setnikar, I. (1958). Experimental study of osmosis through a collodion membrane. The Journal of General Physiology, 42(2), 429-444. http://dx.doi.org/10.1085/jgp.42.2.429. PMid:13587923.

Moonen, H., \& Niefind, H. J. (1982). Alcohol reduction in beer by means of dialysis. Desalination, 41(3), 327-335. http://dx.doi.org/10.1016/ S0011-9164(00)88733-0.

Mueller, N. C., Van der Bruggen, B., Keuter, V., Luis, P., Melin, T., Pronk, W., Reisewitz, R., Rickerby, D., Rios, G. M., Wennekes, W., \& Nowack, B. J. (2012). Nanofiltration and nanostructured membranes-Should they be considered nanotechnology or not? Journal of Hazardous Materials, 211, 275-280. http://dx.doi. org/10.1016/j.jhazmat.2011.10.096. PMid:22154870.

Olmo, A. D., Blanco, C. A., Palacio, L., Prádanos, P., \& Hernández, A. (2014). Pervaporation methodology for improving alcohol-free beer quality through aroma recovery. Journal of Food Engineering, 133, 1-8. http://dx.doi.org/10.1016/j.jfoodeng.2014.02.014.

Perpète, P., \& Collin, S. (2000). Influence of beer ethanol content on the wort flavour perception. Food Chemistry, 71(3), 379-385. http:// dx.doi.org/10.1016/S0308-8146(00)00179-5.

Pires, E. J., Teixeira, J. A., Branyik, T., \& Vicente, A. A. (2014). Yeast: the soul of beer's aroma-a review of flavour-active esters and higher alcohols produced by the brewing yeast. Applied Microbiology and Biotechnology, 98(5), 1937-1949. http://dx.doi.org/10.1007/s00253013-5470-0. PMid:24384752.

Purwasasmita, M., Kurnia, D., Mandias, F. C., Khoiruddin, \& Wenten, I. G. (2015). Beer dealcoholization using non-porous membrane distillation. Food and Bioproducts Processing, 94, 180-186. http:// dx.doi.org/10.1016/j.fbp.2015.03.001.

Ruiz-Rodríguez, A., Fornari, T., Jaime, L., Vázquez, E., Amador, B., Nieto, J. A., Yuste, M., Mercader, M., \& Reglero, G. (2012). Supercritical CO extraction applied toward the production of a functional beverage from wine. The Journal of Supercritical Fluids, 61, 92-100. http:// dx.doi.org/10.1016/j.supflu.2011.09.002.

Salles, A. (2015). Anuário 2015. São Paulo: CEVBRASIL.

Silva, A. P., Jager, G., van Zyl, H., Voss, H.-P., Pintado, M., Hogg, T., \& de Graaf, C. (2015). Cheers, proost, saúde: cultural, contextual and psychological factors of wine and beer consumption in Portugal and in the Netherlands. Critical Reviews in Food Science and Nutrition, 57(7), 1340-1349. http://dx.doi.org/10.1080/10408398.2014.9693 96. PMid:26560863.

Sohrabvandi, S., Mousavi, S. M., Razavi, S. H., Mortazavian, A. M., \& Rezaei, K. (2010). Alcohol-free beer: methods of production, sensorial defects, and healthful effects. Food Reviews International, 26(4), 335-352. http://dx.doi.org/10.1080/87559129.2010.496022.

Strejc, J., Siřištová, L., Karabín, M., Almeida e Silva, J. B., \& Brányik, T. (2013). Production of alcohol-free beer with elevated amounts of flavouring compounds using lager yeast mutants. Journal of the Institute of Brewing, 119, 149-155. http://dx.doi.org/10.1002/jib.72.

The Economist Explains. (2013). Research service. Retrieved from: http://www.economist.com/blogs/economist-explains/2013/08/ economist-explains

Vanderhaegen, B., Neven, H., Coghe, S., Verstrepen, K. J., Derdelinckx, G., \& Verachtert, H. (2003). Bioflavoring and beer refermentation. Applied Microbiology and Biotechnology, 62(2-3), 140-150. http:// dx.doi.org/10.1007/s00253-003-1340-5. PMid:12759790.

Verhoef, A., Figoli, A., Leen, B., Bettens, B., Drioli, E., \& Van der Bruggen, B. (2008). Performance of a nanofiltration membrane for removal of ethanol from aqueous solutions by pervaporation. Separation and Purification Technology, 60(1), 54-63. http://dx.doi. org/10.1016/j.seppur.2007.07.044.

Williams, J. A. (2002). Keys to bioreactor selections. Chemical Engineering Progress, 98, 34-41. 